\title{
Case report: new onset heart failure in congenitally corrected transposition of the great arteries, dextrocardia, and situs inversus in an octogenarian
}

\author{
Casondra Moore* ${ }^{*}$ and Abdulfatah Osman
}

\begin{abstract}
Background: Congenitally corrected transposition of the great arteries (ccTGA) is a rare anomaly comprising a minimal portion of congenital heart disease cases. Some patients are not identified until adulthood. A minority of these patients maintain normal functional status into the seventh decade and generally only when no other anomalies exist. We describe a case of ccTGA, dextrocardia, and situs inversus in the oldest patient diagnosed with these congenital abnormalities to date.

Case presentation: An 83 year old female with known dextrocardia presented with dyspnea and was diagnosed with ccTGA, situs inversus, and new onset heart failure.

Conclusions: The factors that lead to a delayed presentation of systemic right ventricular failure in ccTGA remain ill-defined. Common adult acquired secondary causes of heart failure, such as hypertension and coronary artery disease, likely play a role in patients with congenital heart disease. Aggressive screening and management of these co-existing diseases may improve overall outcomes in adult patients with congenital heart disease.
\end{abstract}

Keywords: Congenitally corrected transposition, Dextrocardia, Systemic ventricular failure

\section{Background}

Congenitally corrected transposition of the great arteries (ccTGA) is a rare complex congenital heart disease characterized by atrioventricular and ventriculo-arterial discordance. Dextrocardia, along with other intra-cardiac defects, are common findings in this population [1-3]. Situs inversus, identified by inverted atria, occur less frequently in these patients, representing only $34 \%[4,5]$. If no associated intra-cardic abnormalities coexist with ccTGA, these patients may go undiagnosed until adulthood [1]. Generally by the fourth decade, systemic right ventricle (RV) dysfunction is clinically apparent [3]. We present the case of a patient with known dextrocardia who was diagnosed with ccTGA and systemic RV dysfunction at 83-years-old. This case, with the constellation of ccTGA,

\footnotetext{
* Correspondence: casondra.moore@gmail.com

Department of Cardiovascular Medicine and Internal Medicine, Michigan State University/Genesys Regional Medical Center/Ascension Health, One Genesys Pkwy, Grand Blanc, MI 48430, USA
}

dextrocardia, and situs inversus, represents the oldest patient diagnosed with these congenital abnormalities to date.

\section{Case presentation}

An 83-year-old female with dextrocardia, hypertension, diabetes mellitus type 2 , and history of right breast cancer treated with radiation and lumpectomy 15 years prior, presented to our hospital for evaluation of dyspnea. Vitals demonstrated blood pressure $179 / 91 \mathrm{mmHg}$, heart rate $71 \mathrm{bpm}$, respiratory rate of 25 breaths/min, and oxygen saturation of 93\% with 31 of oxygen via nasal cannula. On physical examination dextrocardia was noted. A laterally displaced right-sided point of maximal impulse with a heave was palpated. The heart rhythm was regular with a pronounced pulmonary component of the second heart sound. Fine bibasal crackles, and minimal lower extremity edema were also present. Blood work revealed a pro-BNP of $1450 \mathrm{pg} / \mathrm{ml}$ (reference range

(c) The Author(s). 2018 Open Access This article is distributed under the terms of the Creative Commons Attribution 4.0 International License (http://creativecommons.org/licenses/by/4.0/), which permits unrestricted use, distribution, and reproduction in any medium, provided you give appropriate credit to the original author(s) and the source, provide a link to the Creative Commons license, and indicate if changes were made. The Creative Commons Public Domain Dedication waiver (http://creativecommons.org/publicdomain/zero/1.0/) applies to the data made available in this article, unless otherwise stated. 


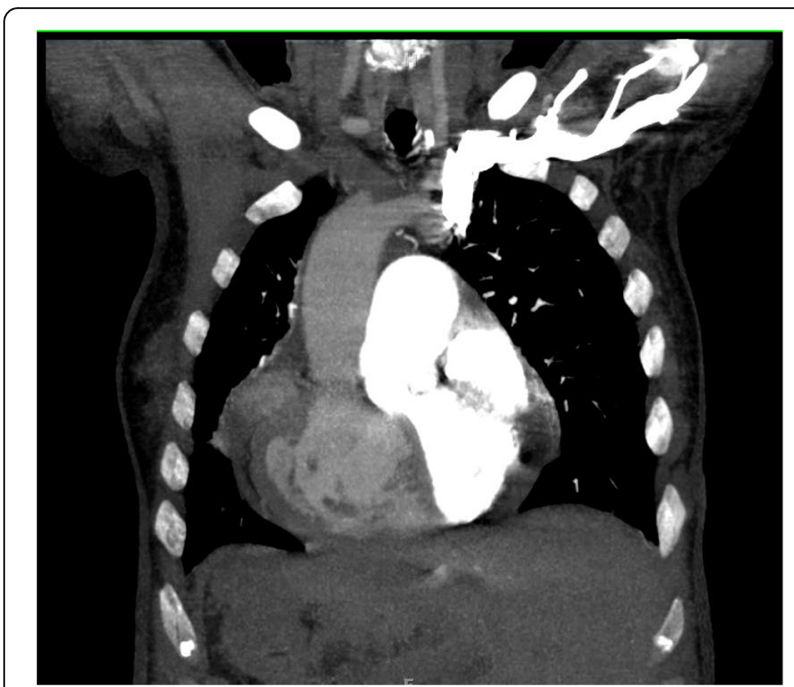

Fig. 1 Chest computed tomography angiogram illustrating the dextrocardia with situs inversus. The liver can be seen beneath the diaphragm on the patient's left

0-1800 $\mathrm{pg} / \mathrm{ml}$ ) with a negative troponin. Chest radiograph and chest computed tomography exhibited situs inversus, dextrocardia with right aortic arch, and small non-loculated pleural effusions (Fig. 1, file name: image 1 CT). An electrocardiogram (ECG) demonstrated sinus rhythm with dextrocardia, nonspecific intraventricular conduction delay with nonspecific $\mathrm{T}$ wave changes, and premature atrial contractions. No other conduction abnormalities were present on ECG (Fig. 2, file name: image2 ECG).
Transthoracic echocardiograph determined that the aorta arose from the morphologic right ventricle (RV), which was identified by a more apical displacement of the septal leaflet of tricuspid valve relative to the mitral valve, prominent trabeculation, and the presence of a moderator band (Fig. 3, file name echo images 1). The systemic RV was dilated and severely hypertrophic with global hypokinesis and moderately reduced ejection fraction (EF) of 30-35\%. The pulmonary artery arose from the morphological left ventricle (LV) (Fig. 4, file name: echo images 2). The anatomic LV was relatively small and thin with hyperdynamic function. The anatomic LV outflow (subpulmonary) tract appeared normal in size without significant elevation in peak gradients measured on Doppler interrogation. There were no signs of significant subpulmonary structural abnormalities obstructing flow through the LV outflow tract or pulmonary valve. The right atrium was small in size while the left atrium was moderately to severely dilated. Mild to moderate tricuspid regurgitation was present along with mild insufficiency of the pulmonary, mitral, and aortic valves. By peak mitral regurgitation velocity, peak pulmonary arterial systolic pressure was estimated at $38-40 \mathrm{mmHg}$.

The patient was started on heart failure therapy with furosemide $20 \mathrm{mg}$ intravenous twice daily, Lisinopril $5 \mathrm{mg}$ daily, and carvedilol $3.125 \mathrm{mg}$ twice daily. After therapy, the patient improved and was discharged home. She was closely followed in the cardiology clinic over the next 10 months where heart failure medical therapy was optimized. The patient's medication list included

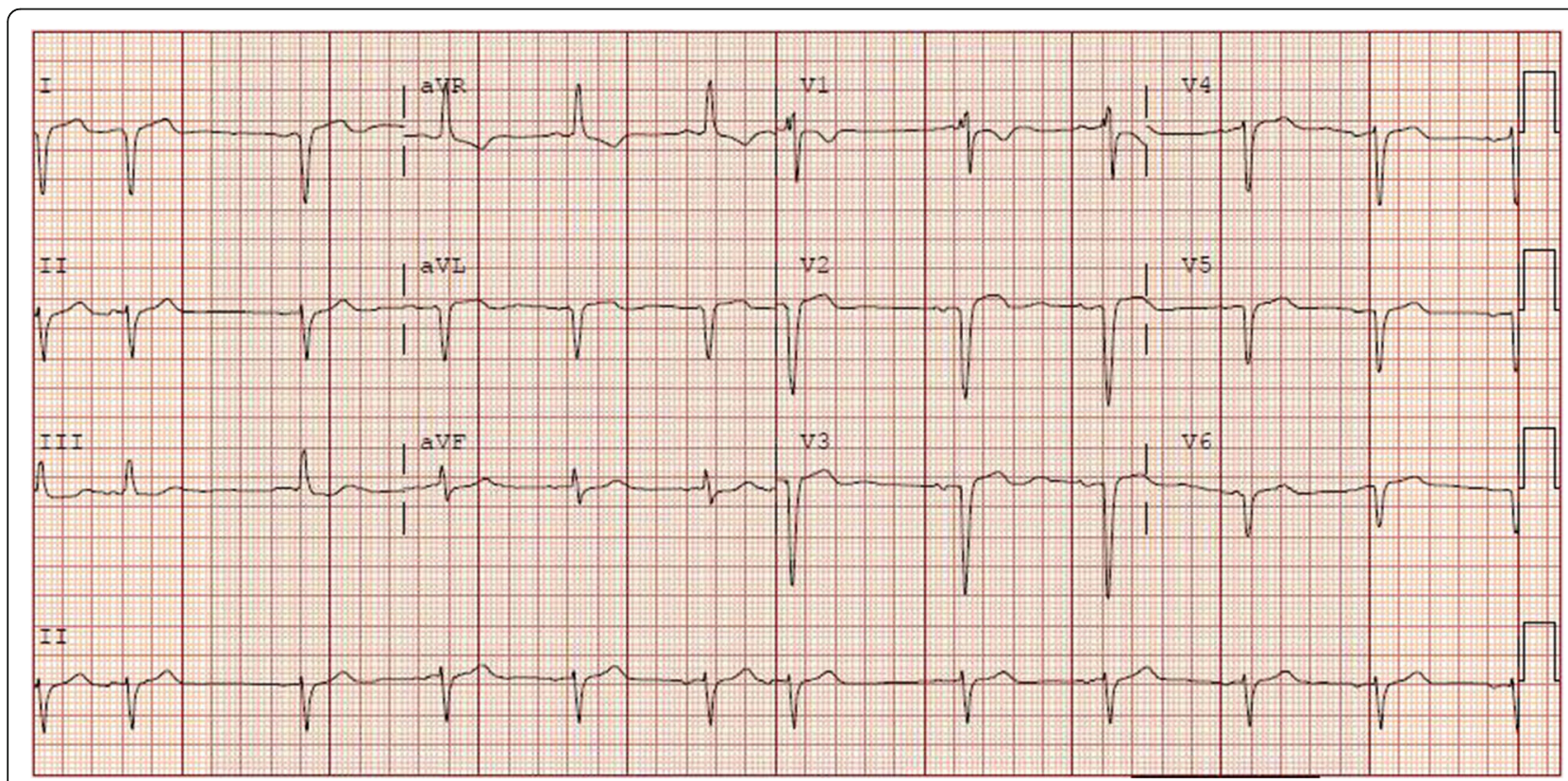

Fig. 2 Electrocardiogram with sinus rhythm with dextrocardia, nonspecific $T$ wave changes, and premature atrial contractions 


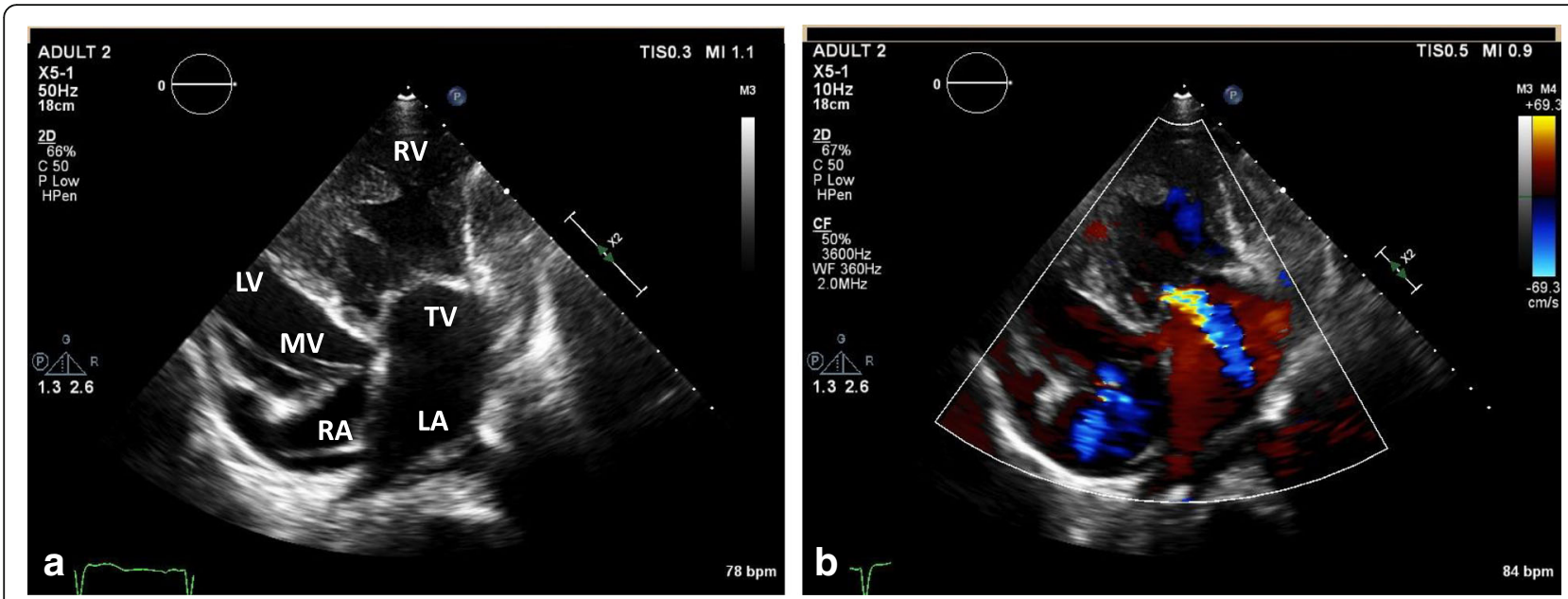

Fig. 3 Congenitally corrected transposition of the great arteries. a, The more apically positioned valve on the right is the anatomic indicator of the tricuspid valve which communicates with a hypertrophied right ventricle. $\mathbf{b}$, Mild to moderate regurgitation of the tricuspid valve. LV: left ventricle, MV: mitral valve, RA: right atrium, RV: right ventricle, TV: tricuspid valve, LA: left atrium

Lisinopril $40 \mathrm{mg}$ daily, furosemide $20 \mathrm{mg}$ daily, carvedilol $12.5 \mathrm{mg}$ twice daily, and spironolactone $25 \mathrm{mg}$ daily. The patient presented 1 year later to the hospital with complaints of increasing dyspnea, lower extremity edema, and orthopnea. On this admission, vitals included blood pressure $177 / 96 \mathrm{mmHg}$, heart rate $100 \mathrm{bpm}$, respiration 22 breaths/min, and oxygen saturation of $92 \%$ on 21 of oxygen via nasal cannula. Pro-BNP was elevated at $5276 \mathrm{pg} / \mathrm{ml}$. A repeat echocardiogram demonstrated a decrease in systemic RV function to an EF of 20-25\%. Tricuspid regurgitation was worse and pulmonary artery systolic pressure rose to $52 \mathrm{mmHg}$. Intravenous diuretic therapy was initiated with furosemide $40 \mathrm{mg}$ twice daily. While hospitalized, the patient developed atrial fibrillation with rapid ventricular response, which was treated with apixaban $2.5 \mathrm{mg}$ twice daily and up titration of rate-controlling medications with an increase in carvedilol to $25 \mathrm{mg}$ twice daily. Following diuresis, with associated improvement of symptoms, the patient was released from the hospital. The patient is currently closely monitored in the heart failure clinic.

\section{Discussion}

In modern practice, the majority of cases of ccTGA are diagnosed antenatally via fetal ultrasound. If ccTGA is not recognized antenatally and there are not significant associated cardiac defects, ccTGA patients are likely to remain asymptomatic until the fourth or fifth decade [3]. After the fifth decade, the incidence of congestive heart
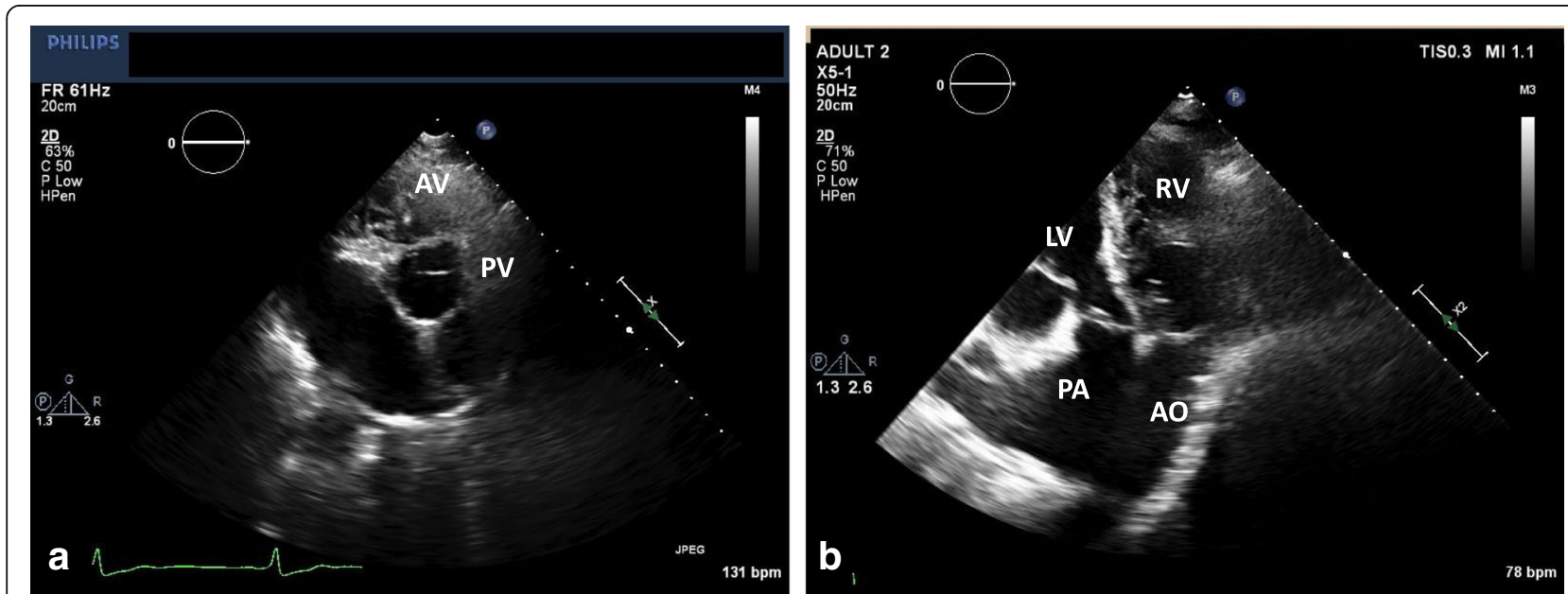

Fig. 4 Parallel position of the great arteries. a, Parasternal short axis view demonstrating anterior placement of the aorta compared to the pulmonic valve. b, Modified apical four-chamber outflow view with great arteries seen in parallel. AV: aortic valve. PV: pulmonic valve 
failure and systemic RV dysfunction increases despite the lack of associated abnormalities. The development of RV dysfunction and tricuspid insufficiency are associated with higher mortality in these patients [6]. The exact mechanisms resulting in eventual RV dysfunction are still a subject of debate with a variety of physiologic and anatomic factors believed to be pathogenetically responsible. These mechanisms can include, but are not limited to, insufficient coronary artery blood flow, progressive tricuspid regurgitation, long term exposure of the RV to increased afterload, arrhythmias, conduction abnormalities, and eventual right ventricular hypertrophy (RVH) $[1,2,5,7-9]$. How these factors contribute to the timeline of development of RV dysfunction, allowing some patients to continue to be asymptomatic until the eighth or ninth decades, like our patient, is unclear.

The adaptive capability of the systemic RV to increased afterload may play a role in delay of symptoms. At the molecular level, maladaptive RVH displays greater impairment of angiogenesis, adrenergic signaling, and glucose metabolism than adaptive RVH. Although determinants of the adaptive response, and its timeline, of a given RV to increased afterload, including fetal gene switching among others, are not well defined, candidate genes and transcription factors have already been described [10]. The capacity of the systemic RV in our patient to favorably respond to increasing systemic pressures since birth may have possibly been related to an adaptive RVH response as a phenotypic expression of a protective genetic profile.

In addition to eventual systemic RV dysfunction, all ccTGA patients have some degree of conduction system abnormalities resulting from the unusual location of the AV node and unique path of the His bundle $[1,2]$. The abnormal positioning of the conduction system increases the risk for fibrosis of the conduction system with a progressive incidence of complete atrioventricular (AV) block of roughly $2 \%$ per year [11]. The rates of complete AV block appear to vary between patients with ccTGA situs solitus compared to those with situs inversus. In one cohort study, there was a decreased incidence of non-surgical complete AV block in the situs inversus group compared to patients with situs solitus [5]. It was theorized that the associated malalignment of the atrial and ventricular septum associated with situs solitus leads to increased susceptibility to atrioventricular block [5]. The decreased likelihood of heart block in ccTGA with situs inversus may contribute to improved long term survival, as in our case.

Life expectancy in patients with ccTGA is known to be reduced compared to normal individuals $[1,2]$. As a result, not much data exist regarding the role common adult acquired secondary causes of systemic ventricular failure, such as hypertensive heart disease, diabetes mellitus, or coronary artery disease, may play in systemic RV failure in ccTGA. Only a handful of published cases described acute coronary syndrome (ACS) in ccTGA patients who were diagnosed with varying degrees of coronary artery disease [12-14]. The degree to which coronary artery disease may contribute to systemic RV dysfunction and long-term outcomes has yet to be established in the aging population with ccTGA.

As stated previously, the incidence of systemic RV dysfunction increases with age leading to signs and symptoms of congestive heart failure [6]. Unfortunately, data from clinical trials aimed at guiding clinicians on how to medically manage heart failure in congenital heart disease are lacking. A few small trials of patients with a systemic RV have demonstrated a decrease in heart failure biomarkers with the use of agents targeting the renin-angiotensin-aldosterone system without a clear impact on morbidity and mortality [15-17]. Currently, in symptomatic patients with systemic RV dysfunction medical therapies for congestive heart failure from the systemic LV heart failure guidelines are applied with caution [15]. Larger scale trials of medical therapy for congestive heart failure in the congenital heart disease population will become increasingly imperative as the number of aging patients with congenital heart disease continues to grow.

\section{Conclusions}

This case represents the oldest reported patient to date with dextrocardia and newly diagnosed congenitally corrected transposition of the great arteries with situs inversus. A variety of factors may have contributed to delayed onset of heart failure until the ninth decade. However, determinants of successful adaptation of the RV to systemic afterload including the interaction with acquired heart diseases in this elderly population of ccTGA remain elusive. Understanding these factors may shed light on the RV potential to favorably adjust to increasing afterload in a variety of congenital as well as acquired conditions associated with pulmonary hypertension. Finally, by earlier screening and diagnosis of ccTGA, the adult cardiologist can potentially help preserve the systemic RV function through careful monitoring of tricuspid valve function with early intervention as needed, and by meticulous surveillance and aggressive treatment of acquired adult cardiac diseases to improve the survival and quality of life of this vulnerable patient population.

\section{Abbreviations}

AV: Atrioventricular; bpm: Beats per minute; breaths/min: Breaths per minute; ccTGA: Congenitally corrected transposition of the great arteries;

ECG: Electrocardiogram; EF: Ejection fraction; LV: Left ventricle; mg: Milligrams; mmHg: Millimeters of mercury; RV: Right ventricle; RVH: Right ventricular hypertrophy 


\section{Availability of data and materials}

Data sharing not applicable to this article.

\section{Authors' contributions}

All authors helped to draft the manuscript and approved the final manuscript.

\section{Competing interest}

The authors have none to declare.

\section{Ethics approval and consent to participate}

Not applicable.

\section{Consent for publication}

The patient's legal guardian gave consent to publish this case report.

\section{Publisher's Note}

Springer Nature remains neutral with regard to jurisdictional claims in published maps and institutional affiliations.

Received: 25 April 2018 Accepted: 25 June 2018

Published online: 03 August 2018

\section{References}

1. Warnes CA. Transposition of the great arteries. Circulation. 2006; https://doi. org/10.1161/CIRCULATIONAHA.105.592352.

2. English C. Flack and Thomas P. Graham (2012). Congenitally Corrected Transposition of the Great Arteries, Congenital Heart Disease - Selected Aspects, Prof. P. Syamasundar Rao (Ed.), ISBN: 978-953-307-472-6, InTech, Available from: https://www.intechopen.com/books/congenital-heartdisease-selected-aspects/congenitally-corrected-transposition-of-the-greatarteries. Accessed: 1 Aug 2017.

3. Hornung TS, Calder L. Congenitally corrected transposition of the great arteries. Heart. 2010; https://doi.org/10.1136/hrt.2008.150532.

4. Biliciler-Denkatas G, Feldt RH, Connolly HM, Weaver AL, Puga FJ, Danielson GK. Early and late results of operations for defects associated with corrected transposition and other anomalies with atrioventricular discordance in a pediatric population. J Thorac Cardiovasc Surg. 2001;122:234-41.

5. Oliver JM, Gallego P, Gonzalez AE, Sanchez-Recalde A, Brett M, Polo L, Gutierrez-Larraya F. Comparison of outcomes of adults with congenitally corrected transposition with situs inversus vs situs solitus. Am J Cardiol. 2012; https://doi.org/10.1016/j.amjcard.2012.07.039.

6. Graham TP Jr, Bernard YD, Mellen BG, Celermajer D, Barumagartner H, Cetta $F$, et al. Long-term outcome in congenitally corrected transposition of the great arteries: a multi-institutional study. J Am Coll Cardiol. 2000;36:255-61.

7. Presbitero P, Somerville J, Rabajoli F, Stone S, Conte MR. Corrected transposition of the great arteries without associated defects in adult patients: clinical profile and follow up. Br Heart J. 1995; https://doi.org/10. 1136/hrt.74.1.57

8. Beauchesne LM, Warnes CA, Connolly HM, Ammash NM, Tajik AJ, Danielson GK. Outcome of the unoperated adult who presents with congenitally corrected transposition of the great arteries. J Am Coll Cardiol. 2002;40:285-90.

9. Tan JLT, Prat D, Gatzoulis MA, Gibson S, Henein MY, Li W. The right ventricular response to high afterload: comparison between atrial switch procedure, congenitally corrected transposition of the great arteries, and idiopathic pulmonary arterial hypertension. Am Heart J. 2007; https://doi. org/10.1016/j.ahj.2006.12.027.

10. Ryan J, Archer S. The Right Ventricle in Pulmonary Arterial Hypertension: Disorders of Metabolism, Angiogenesis and Adrenergic Signaling in Right Ventricular Failure. Circ Res. 2014;115:176-88.

11. Huhta JC, Maloney JD, Ritter DG, Feldt RH. Complete atrioventricular block in patients with atrioventricular discordance. Circulation. 1983;67:1374-7. doi.org/10.1161/01.CIR.67.6.1374

12. Ozturk O, Ozturk U, Nergiz S, Karahan MZ. Primary PCl in a patient with congenitally corrected transposition of the great arteries. Int I Cardiovasc Acad. 2016; https://doi.org/10.1016/j.jjac.2016.04.004.

13. Ozturk S, Erdem F, Ozturk S, Ayhan S. Successful thrombolytic therapy in a patient with congenital corrected transposition of the great arteries. Acta Med Acad. 2016. https://doi.org/10.5644/ama2006-124.172.
14. Lampropoulos, KM, D Kotsas, TA lliopoulos. Acute coronary syndrome in congenitally corrected transposition of the great arteries. BMJ Case Reports. Published online 2013. doi: https://doi.org/10.1136/bcr-2012-008354.

15. Budts W, Roos-Hesselink J, Radle-Hurst T, Eicken A, McDonagh TA, et al. Treatment of heart failure in adult congenital heart disease: a position paper of the working group of grown-up congenital heart disease and the heart failure association of the European Society of Cardiology. Eur Heart J. 2016; 37:1419-27. https://doi.org/10.1093/eurheartj/ehv741.

16. Tutarel O, GP Meyer H, Bertram A, Wessel BS, Westhoff-Bleck M. Safety and efficiency of chronic ACE inhibition in symptomatic heart failure patients with a systemic right ventricle. Int J Cardiol. 2012;154:14-6.

17. Dos L, Pujadas S, Estruch M, Mas A, Ferreira-Gonzalez I, Pijuan A, et al. Eplerenone in systemic right ventricle: double blind randomized control trail. The EVEDES study. Int J Cardiol. 2013;168:5167-73.

\section{Ready to submit your research? Choose BMC and benefit from:}

- fast, convenient online submission

- thorough peer review by experienced researchers in your field

- rapid publication on acceptance

- support for research data, including large and complex data types

- gold Open Access which fosters wider collaboration and increased citations

- maximum visibility for your research: over $100 \mathrm{M}$ website views per year

At BMC, research is always in progress.

Learn more biomedcentral.com/submissions 